\title{
PERAN “LOCAL POP UP BOOKS" PADA PEMBELAJARAN BAHASA INGGRIS UNTUK ANAK USIA DINI
}

\author{
Desiani Natalina M. ${ }^{1}$
}

\begin{abstract}
ABSTRAK
Memperkenalkan bahasa Inggris pada anak usia dini menjadi trend yang terjadi di Indonesia. Para orang tua banyak yang menginginkan anak-anaknya untuk bisa berbahasa Inggris sedini mungkin. Hal ini berpengaruh pada aktifitas anak di sekolah karena sekolah dituntut pula untuk bisa memfasilitasi keinginan orangtua tersebut. Lembaga pendidikan anak usia dini dari mulai kober dan taman kanakkanak mulai memperkenalkan bahasa Inggris. Hal ini berpengaruh pada kreatifitas guru mengemas kegiatan berbahasa Inggris di sekolah untuk anak usia dini. Salah satu alternatif cara memperkenalkan bahasa Inggris pada anak usia dini adalah dengan memanfaatkan pop up books yang bernuansa keindonesiaan. Makalah ini akan menyajikan bahan pemikiran mengenai pemanfaatan "Local Pop Up Books" yang menggambarkan budaya lokal daerah di Indonesia untuk memperkenalkan bahasa Inggris pada anak usia dini di Indonesia.
\end{abstract}

Kata kunci : local pop up books, pembelajaran bahasa Inggris untuk AUD

\section{A. PENDAHULUAN}

Bahasa Inggris yang merupakan bahasa pergaulan internasional di dunia mulai diperkenalkan sedini mungkin di Indonesia. Anak usia dini mulai diperkenalkan dengan bahasa Inggris dengan harapan bahwa mereka bisa mempelajarinya dengan cepat dan fasih menggunakannya seperti apa yang dikatakan oleh Puhafl, Christian, and Rhodes (dalam Zubairi\&Sarudin, 2009) bahwa "successful foreign language programmes shared several common features including (a) an early start for students to learn languages...". Anak usia dini yang berada pada tahap "Golden Age" menjadi sasaran yang paling empuk untuk mengasah kemampuan bahasa mereka sehingga banyak taman kanak-kanak yang memperkenalkan bahasa Inggris pada aktifitas pembelajaran di sekolah. Namun perlu dipahami juga bahwa memperkenalkan bahasa Inggris yang notabene merupakan bahasa asing di Indonesia memberikan nuansa dan tuntutan tersendiri. Nuansa yang dimunculkan adalah karena posisinya sebagai bahasa asing maka bahasa Inggris jarang sekali atau bahkan tidak pernah digunakan dalam kehidupan sehari-hari anak. Sehingga jika di sekolah diperkenalkan bahasa Inggris maka belum tentu anak bisa memanfaatkannya di luar sekolah ketika berinteraksi dengan yang lain. Tuntutannya adalah karena bahasa Inggris merupakan bahasa asing maka guru harus mampu mentransfer bahasa sesuai dengan tingkat pekembangan anak dan hakikat bahasa Inggri sebagai bahasa asing di Indonesia. Ketika mentransfer bahasa Inggris pada anak inilah dibutuhkan kreatifitas, kesungguhan dan energi yang luar biasa dari seorang guru. Musthafa (2001) mengungkapkan bahwa jika seorang guru

1 Dosen UPI kampus Tasikmalaya 
ingin bahasa Inggris yang diperkenalkan berhasil untuk bisa dimanfaatkan oleh anak maka anak harus

Exposure to the language (where learners get exposed to language in use which can serve as examples to learn from), 2. Engagement (where learners get opportunities to use the language for communicative purposes), and 3. Consistent support (where the learners see for themselves that learning the language is useful;and the language they learn is socially recognized as prestigious).

Anak yang diperkenalkan dengan bahasa Inggris haruslah diterjunkan langsung dengan penggunaan bahasa sehingga anak mengalami proses berkomunikasi dengan bahasa tersebut dan mendapatkan dukungan yang konsisten dari orang-orang di sekitarnya salah satu diantaranya adalah guru. Jika guru tidak konsisten menggunakan bahasa Inggris dalam berkomunikasi, niscaya anak pun tidak melihat bahasa itu sebagai sesuatu yang berharga untuk dipelajari. Gurupun dituntut untuk menciptakan lingkungan yang akan mendukung proses anak mengalami (Cameron, 2001:20) dan berkomunikasi dengan bahasa Inggris di sekolah.

Banyak cara yang dapat dimanfaatkan oleh guru-guru di PAUD untuk memperkenalkan bahasa Inggris. Salah satu diantaranya adalah dengan menggunakan "lokal Pop Up Books" sebagai salah satu alternatif ataupun pilihan media. "Pop up books" adalah buku dalam bentuk tiga dimensi atau buku yang bergerak (wikipedia.org). "pop up books" merupakan salah satu jenis dari "picture book" (Bolton \& Wait, 2007; Jalongo, 2004; Mitchell, 2002 dalam Al Tiyb Al Khaiyali, 2013). Karena tampilannya yang lebih menarik dibandingkan dengan buku cerita biasa maka anak-anak lebih tertarik untuk melihat dan membukanya karena bentuknya yang tiga dimensi. Lokal pop up books adalah pop up book yang konten atau isinya disesuaikan dengan budaya lokal di Indonesia.

\section{B. PEMBAHASAN}

\section{Pembelajaran Bahasa Inggris untuk Anak Usia Dini}

Mengajarkan bahasa Inggris pada anak tentu saja berbeda dengan mengajarkan bahasa Inggris pada orang dewasa ataupun remaja. Karakteristik anak yang cenderung "moody" , aktif (tidak bisa diam pada satu posisi tertentu untuk waktu yang lama), dan gampang bosan . Namun ketika anak usia dini menemukan sesuatu yang menarik perhatian mereka maka mereka akan dengan senang hati menggali dan mencermati hal yang baru. Hal inipun berpengaruh pada bagaimana guru menciptakan lingkungan yang mampu memfasilitasi atau mengakomodasi anak untuk belajar bahasa Inggris dengan menyenangkan, menarik dan tidak membosankan. Beberapa prinsip yang harus diperhatikan oleh guru ketika mengajarkan bahasa Inggris untuk anak usia dini (Suhartatik, 2008) adalah sebagai berikut
a. Aktifitas pembelajaran haruslah melibatkan kegiatan sensori-motorik bagi anak
b. Meningkatkan variasi mengajar di kelas
c. Menyiapkan reinforcement
d. Memotivasi anak bahwa belajar bahasa Inggris itu menyenangkan 
e. Suasana belajar bahasa Inggris haruslah santai dan menyenangkan.

Memunculkan lingkungan yang bermakna pada anak sebagai sarana mereka belajar bahasa Inggris menjadi hal penting juga untuk guru perhatikan. Wagner (1989) mengemukakan bahwa kemampuan bahasa anak secara alami dikuasai pada konteks interaksi verbal yang bermakna dan kegiatan-kegiatan berbahasa.

\section{Local Pop Up Books}

Ide memanfaatkan "lokal pop up books" untuk mengenalkan bahasa Inggris untuk anak berawal dari tampilan pop up books yang berbeda dari umumnya buku bacaan. Pop up books yang dikemas dengan lipatan kertas yang bisa muncul (pop out) ketika dibuka, digeser sehingga keluar gambar yang dicari, ataupun dilipat diantara halamannya. Tampilan yang berbeda dengan bentuk tiga dimensi dengan jenis buku lainnya, membuat pop up book lebih diminati oleh anak usia dini. Yang dimaksud dengan "Lokal pop up books adalah pop up book yang dibuat oleh orang Indonesia sendiri dengan isi cerita disesuaikan dengan budaya lokal Indonesia. Isi cerita mengenai hal-hal yang sering dan mudah ditemui oleh anak-anak dalam kehidupan sehari-hari mereka. Sehingga anak-anak dibuat mudah untuk mengerti isi cerita yang terkandung dalam "Local Pop up books". Hanya bahasanya saja yang menggunakan bahasa Inggris sehingga anak mudah untuk mengasosiasikan bahasa Inggris dengan gambar yang dilihatnya melalui "local pop up books". "Local Pop up books" yang termasuk pada kategori "picture book" memenuhi aspek - aspek yang diantaranya adalah ilustrasi, menarik, autentik, berhubungan dengan budaya, mudah untuk dibaca. Berikut ini ilustrasi aspek-aspek yang harus dipenuhi pada buku bergambar:

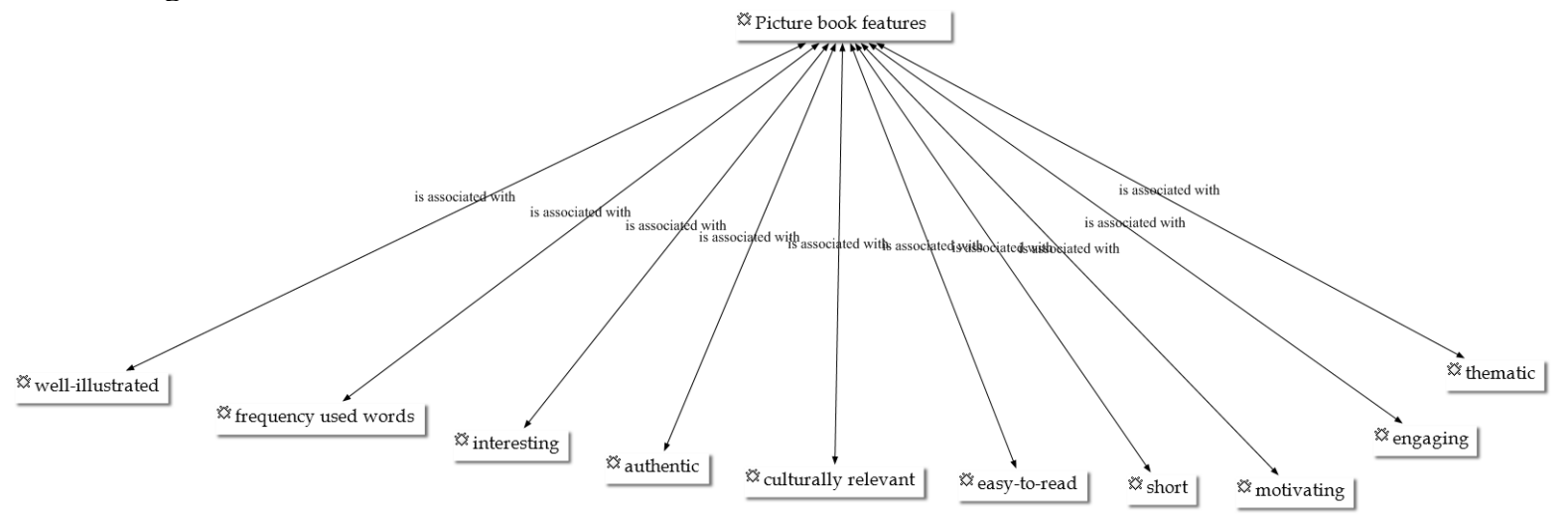

Gambar 1: Attributes of Children's Picture Books ( Al Tiyb Al Khaiyali, 2013)

Jika semua aspek terpenuhi maka "local pop up books" akan diminati oleh anak dan menjadi salah satu alternatif media untuk anak belajar bahasa Inggris.

\section{Peran "Local Pop Up Books" pada pembelajaran Bahasa Inggris untuk Anak Usia Dini}

Pada dasarnya Lokal Pop up books secara umum akan menumbuhkan ketertarikan anak usia dini untuk mengenal buku dan kegiatan membaca, sehingga akan tumbuh di hati mereka rasa senang untuk membaca buku. Jika mereka senang 
maka merekapun akan terus termotivasi untuk membaca buku (Rosenblatt, 1994). Selain itu anak akan menghubungkan "prior knowledge" mereka dengan isi cerita bahasa Inggris (Al Tiyb Al Khaiyali, 2013) dari "local pop up books". Berikut adalah manfaat "local pop up books" secara rinci

a. Kegiatan awal membaca

1) memperkenalkan anak dengan kesenangan pada kegiatan membaca

2) belajar bagaimana teks ditulis secara berjajar lurus

3) belajar mengenal spasi antar kata, huruf kapital, huruf kecil

4) berpartisipasi dalam kegiatan berbahasa di sekolah

5) belajar meniru kalimat yang bermakna untuk dirinya sehingga bisa dibacakan kembali dengan nyaring ataupun diceritakan kembali kepada orang lain

6) mendengarkan ritme, lirik, nyanyian sehingga bisa menyanyikannya kembali

7) mulai mempelajari alfabet (Cameron, 2001: 139)

8) Mendengarkan lafal, karakterisasi, dan infleksi (tekanan atau intonasi) yang sesuai ketika cerita dibacakan oleh guru (Krashen dalam Fedyk, 2014)

\section{b. Kebermaknaan}

Isi dari "Local pop up books" haruslah menceritakan suatu hal yang anak temui sehari-hari ataupun berhubungan dengan kehidupan anak-anak. Banyak pop up books di Indonesia yang merupakan buku-buku impor dengan isi bacaan yang menceritakan kehidupan anak-anak di negeri orang lain dan berbanding terbalik dengan kehidupan anak-anak di Indonesia. Salah satu contohnya ketika sebuah pop up book dengan tema "binatang" menceritakan berbagai macam jenis binatang. Topik yang dikemukakan adalah "Birds". Ada 4 jenis burung yang diceritakan yaitu flamingo, ostrich, hummingbird, dan penguin. Keempat jenis burung tersebut akan sangat sulit ditemui secara nyata oleh anak-anak karena anak-anak belum pernah melihatnya terkecuali untuk anak-anak yang sering menonton televisi atau datang ke kebun binatang. Saya Anak yang sering menonton TV maka akan mudah mengenali gambar "penguin" dan "ostrich" karena adanya serial TV yang menayangkan itu. Sedangkan yang lainnya akan terasa tidak bermakna karena anak tidak pernah menemui sebelumnya sehingga tidak merasa perlu. Disinilah peran guru akan sangat dituntut banyak karena harus membantu anak memahami isi buku sehingga bermakna untuk anak. Vigotsky (Cameron, 2001: 6) mengemukakan bahwa

People play important roles in helping children to learn, bringing objects and ideas to their attention, talkong while playing and about playing, reading stories, asking questions. In a whole range of ways, adult mediate the world for children and make it accessible to them.

Mungkin beberapa guru setelah membaca pop up books akan mengajak anak melihat tayangan yang akan mengenalkan anak pada binatang yang belum pernah dijumpai, atau mengajak ke kebun binatang jika tempat tersebut mudah dijangkau dan binatang-binatang yang dimaksud ada disana. Oleh sebab itu pemilihan pop up books pun harus dicermati agar bermakna dan mudah dipahami oleh anak usia dini. "Local pop up books" menjadi salah satu alternatif karena disesuaikan dengan budaya lokal Indonesia ataupun hal-hal yang ditemui sehari-hari oleh anak-anak di 
Indonesia sehingga bermakna dan mudah untuk dipahami seperti apa yang dikemukakan oleh Ghosn (2002) bahwa "picture books provides authentic "natural" language context that stimulates meaningful and motivating space for language learning". Salah satu contoh adalah pop book dengan topik "Tasik Fair" yang menceritakan hal-hal dan kegiatan di pasar malam. Di Indonesia khususnya di Jawa Barat, anakanak umumnya mengenal pasar malam karena sering ditemui sewaktu-waktu. Terlebih pasar malam di Indonesia sering berpindah tempat merambah pelosokpelosok dengan memanfaatkan lahan kosong di sekitar rumah penduduk. Karena guru yang membuat pop up book berasal dari Tasikmalaya Jawa Barat dan kegiatan "Tasik Fair" diselenggarakan setiap tahun, maka Ia menampilkan topik "Tasik Fair" dengan rangkaian kegiatan yang diceritakan dengan bahasa Inggris.

Mengenalkan bahasa Inggris sebagai bahasa asing di Indonesia melalui "local pop up books" akan mempermudah anak untuk mengasosiasikan (Vigotsky, 1978) apa yang ia alami dengan bahasa baru yang ia dapatkan. Guru mengakomodasi (Piaget; Calderon, 2007 ) lingkungan belajar dengan menampilkan topik-topik yang bermakna untuk anak usia dini.

a. Melatih Motorik Halus

Pada "local pop up book", bahan pembuatan yang digunakan tidak saja kertas yang halus yang biasa digunakan untuk buku, tetapi bahan-bahan lain yang bisa membantu siswa memahami makna bacaan. Sebagai contoh ketika topik "Tasik Fair" yang dimunculkan, maka ada halaman yang menceritakan penjual balon. Gambargambar balon atau "baloon" ini disajikan dengan tidak saja memunculkan variasi warna balon tetapi juga menggunakan karet balon seperti di kehidupan sehari-hari anak ketika menjumpai balon.

Anak tidak saja terlatih kognitif dan bahasa Inggrisnya saja tetapi juga anak terlatih motorik halusnya karena dengan membuka "local pop up books" ia bisa meraba, merasakan perbedaan tekstur ataupun jenis bahan yang digunakan.

\section{b. Mengenal dan membedakan warna}

Warna menjadi unsur penting dalam "local pop up books" karena tidak saja akan menarik mata pembaca untuk melihat tapi warnapun akan mempresentasikan makna yang terkandung pada sebuah gambar. Anak tidak saja mengenal warna dalam bahasa Inggris tetapi juga mampu membedakan warna yang dihubungkan dengan "prior knowledge" anak. Sebagai contoh jika biasanya anak melihat ayam dengan warna putih tapi kemudian dalam buku, warna yang ditampilkan untuk ayam menjadi merah muda, maka anak akan bertanya karena tidak sesuai dengan apa yang dijumpai anak sehari-hari.

\section{c. Melatih Kreatifitas}

"Local pop up books" akan melatih kreatifitas guru dan anak. Melatih kreatifitas guru karena pada dasarnya "local pop up book" bisa dibuat sendiri oleh guru. Jika "local pop up book" yang digunakan bukan buatan guru sendiri maka gurupun akan dituntut kreatifitasnya dalam menceritakan isi pop up books agar mudah dimengerti oleh anak usia dini. Kreatifitas siswapun akan digali jika "local 
pop up books" memunculkan bagian-bagian hilang yang harus diisi anak. Sebagai contoh, jika "local pop up book" yang didalamnya terdapat gambar ayam dan gambar tersebut masih kosong belum diberikan bulu-bulu ayam, maka anak bisa berkreasi dengan menempelkan bulu ayam asli, bulu ayam bohongan (kapas, kertas putih), ataupun mewarnainya.

Kreatifitas lain yang muncul dari anak adalah ketika anak mampu untuk menceritakan kembali isi cerita dari "local pop up books" yang dibacanya ataupun menyebutkan kembali kata atau gambar-gambar yang dilihatnya dalam bahasa Inggris. Terkadang hanya dengan melihat gambar ataupun ilustrasi pop up nya saja anak bisa bercerita walaupun belum pernah dibacakan sebelumnya karena kedua hal ini membantu anak sebagai pembaca pemula untuk mengingat dan menyimpan informasi ( Al Tiyb Al Khaiyali, 2013).

Mencermati beberapa manfaat yang dapat digali dengan menggunakan "Local pop up books" secara maksimal, maka pembelajaran bahasa Inggris dapat dilaksanakan secara bervariasi yang salah satu diantaranya dengan menggunakan "local pop up books". Hal ini perlu dipertimbangkan dan dicoba oleh para guru anak usia dini sehingga pembelajaran bahasa Inggris untuk anak usia dini akan menarik dan menyenangkan juga menumbuhkembangkan keterarikan anak akan buku dan kegiatan membaca.

\section{PENUTUP}

"Local pop up books" merupakan salah satu alternatif media yang bisa digunakan untuk pembelajaran bahasa Inggris bagi anak usia dini di Indonesia. Dikatakan sebagai Lokal pop up books karena pembuatnya adalah orang lokal yaitu orang Indonesia dan isi cerita pada "Local pop up books" menceritakan hal-hal yang berhubungan dengan budaya lokal di Indonesia, baik kegiatan ataupun sesuatu yang akan anak- anak Indonesia temui dalam kehidupan sehari-hari mereka. Hal ini dimaksudkan agar kebermaknaan isi cerita pada local pop up books terbangun dengan mudah walaupun bahasa pengantar yang digunakan adalah bahasa Inggris. Anak sebagai pembaca pemula juga pembelajar muda bahasa Inggris akan dengan mudah mengasosiasikan hal-hal yang ia lihat melalui local pop up books dengan "prior knowledge" mereka. Jika anak usia dini sudah tertarik untuk melihat tampilan buku, maka merekapun akan tertarik untuk mengetahui isi cerita. Jika sudah tertarik maka akan terbangun motivasi untuk cinta akan buku dan menyukai membaca.

\section{DAFTAR PUSTAKA}

Al Tiyb Al Khaiyali. 2013. Comprehension Strategy Instruction in Language Learning Classroom Selecting and Using Children's Picture Book For Explicit Reading Comprehension Instruction. International Journal of English Language Teaching. Vol.1, No.2, pp.1-16, December 2013.

Calderón, M. "Adolescent Literacy and English language Learners: An Urgent Issue!” ESL Magazine, pp. 9-14. March/ April 2007 (56).

Cameron Lynn. 2001. Teaching languages to Young Learners. Cambridge University Press. 
Fedyk, Carol. 2014. Reading and L2 Acquisition. The International TEYL Journal. March 2014. Accessed in www.teyl.org on February 2014.

Ghosn, I. (2002) Four good reasons to use literature in primary school ELT, ELT Journal, 56, 2 172-179.

Musthafa. 2001. Teaching English to Young Learners in Indonesia: Essensial Requirements. Educationist. Vol IV No. 2. Juli 2010.

Rosenblatt, L. (1994). The transactional theory of reading and writing. Newark, DE: International Reading Association.

Suhartatik. 2008. Teaching English for Young Learners. Paradigma, Tahun XIII, Nomor 25. Januari-Juni 2008

Vigotsky. 1978. Mind in Society. Cambridge University Press.

Zubairi, A. M., \& Sarudin, I. H. (2009). Motivation to Learn a Foreign Language in Malaysia. GEMA Online Journal of Language Studies, 9 (2), 73-87. 